from what $I$ have since seen on the large vacant orbs of aquarium cod-fishes, Sc.

I have not yet scen the porpoises in the Brighton Aquarium, but suspect that if they contrive to "make themselves at home" there, a careful study of their habits will remove some of the difficulty which Prof. Huxley experiences in believing in their intelligence. IV. Mattiev Wilianis

Instinct

A DIFFICULTy occurrel to me on reading Mr. Lewes's interesting and instructive article on "Instinct" in NATURE of April 10-and as no satisfactory answer offers itself to me, I venture to trouble you with it.

Wherein lies the difference in kind between the actions performed instinctively by animals for the preservation of them. selves or their young, and those actions performed by plants with the same result?

For instance; the Ivy Linaria grows on an old wall; its flowers and the flower-stalls stand out for the sun and insects to visit the little "snap-dragon." But no sooner does the corolla fall, than the peduncle begins to curve inwards to the wall, and usually contrives to tuck its seed-vessel well into the brickwork again. We cannot say of such an action that there is "no alternative open to it ; " and eren if we do, it does not explain it to call it "impulsive," and yet one is not prepared to accept it as an instance of instinct. I shall be grateful for any elucidation.

M.

\title{
Grus vipio
}

I OBSERVE that in your report of the meeting of the Zoological Society on the 6th ult., in your issue of the I 5 th, it is stated, with reference to Grus vipio (scu leucauchen), that "no example of this fine species, so far as was known, had previously been brought alive to Europe." Last autumn, when going over the Zoological Gardens at Amsterdam with the superintendent, Mr. Hegt, I saw there a splendid pair of these birds, which had been purchased for $540 l$, and had bred the same spring, and reared successfully a fine young bird, about two-thirds grown when I saw it in September, destined, as I was informed by Mr. Hegt, for the Berlin Gardens. The collection of cranes at Amsterdam is excecdingly rich, far surpassing either London or Antwerp in this respect. It contained, when I saw it, fourteen out of the fifteen valid species of Grus, comprising, besides the above-mentioned, G. zipio, a splendid pair of $G$. ziridirostris, a fine G. leucogeranus, G. carnuculatus, G. canadensis, G. Americana, G. lorguata, Sc., the desideratum being G. monacha, of Japan.

Culverlea, Winchester, June 2

W. A. Forbes

ON THE SYNTHESIS OF MIARSH-GAS AND

FORAIIC ACID, AND ON THE ELECTRIC DECOMIPOSITION OF CARBONIC OXIDE *

$\mathrm{I}$ connection with the investigation on the electric decomposition of carbonic-acid gas referred to in a previous communication to the Society, I was led to submit a mixture of hydrogen and carbonic-oxide gas to the action of electricity in the induction-tube, the mixed gases being circulated through the tube by means of an appa. ratus which I will not now describe. A contraction was soon observed to have taken place, which at the end of an hour amounted to Io cub. centims. The rate of contraction steadily diminished, and during the fifth hour of the duration of the experiment amounted to only 2 cub. centims. The experiment was stopped, and the gas analyzed with the following results in two several analyses :-

$$
\text { I. }
$$

$$
\begin{aligned}
& \text { Carbonic oxide . 6r.6j | Carbonic oxide . 61'35 } \\
& \text { Hydrogen . : } 32 \cdot 56 \text { Hydrogen . : } 32.34 \\
& \text { Marsh-gas. . } 6.14 \mid \text { Marsh-gas . }: 5 \frac{34}{31} \\
& 100 \cdot 00 \\
& 100.00
\end{aligned}
$$

A small quantity (about 2 per cent.) of nitrogen was

\footnotetext{
* A paper read at the Royal Society by Sir B. C. Brodie, Bart., D.C.L.,
}

also contained in the gas, together with a trace of oxygen, which have been omitted from the calculation.

The result of this reaction is expressed in the following equation :-

$$
\mathrm{CO}+3 \mathrm{H}_{2}=\mathrm{CH}_{4}+\mathrm{H}_{2} \mathrm{O} \text {. }
$$

This fundamental experiment, which constitutes the basis of a new method of chemical synthesis, susceptible of the most varied applications, and of peculiar interest in reference to the explication of natural phenomena, was commenced by me on the roth of January last at Oxford, in the laboratory of my friend and successor in the Chair of Chemistry, Prof. Odling; two analyses of the gas were completed, and the results attained in the course of a week from that date. In a similar experiment made with a mixture of hydrogen and carbonic-acid gas, a contraction also occurred, attended with the formation of water. The gas which resulted from the experiment was found to consist (after the absorption of carbonic acid) of hydrogen and carbonic oxide, together with a little marshgas. Traces of oxygen and nitrogen were also present. Minute drops, too, of an oily liquid appeared in the tube. This liquid, after the conclusion of the experiment, was dissolved in a small quantity of water. The solution was strongly acid and had a pungent taste. It reduced an alkaline solution of terchloride of gold and an ammoniacal solution of nitrate of silver. These reactions are the characteristic properties of formic acid, of which we may infer the synthesis to have been effected according to the equation

$$
\mathrm{H}_{2}+\mathrm{CO}_{2}=\mathrm{H}_{2} \mathrm{CO}_{2} \text {. }
$$

I may avail myself of the present opportunity to place on record the following important facts in reference to the action of electricity on carbonic-oxide gas.

When pure and dry carbonic oxide is circulated through the induction-tube, and there submitted to the action of electricity, a decomposition of the gas occurs, attended with a gradual and regular contraction, which, in the form assumed in my experiments, occurred at the regular rate of about 5 cub. centims. in an hour. Carbonic acid is formed, and simultaneously with its formation a solid deposit may be observed in the inductiontube. This deposit appears as a transparent film of a red-brown colour, lining the walls of the tube. It is perfectly soluble in water, which is strongly coloured by it. The solution has an intensely acid reaction.

The solid deposit in the tube, in the dry condition before it has been in contact with water, is an oxide of carbon. Samples, however, made in different experiments do not present precisely the same composition; but nevertheless they appear to belong to a certain limited number of forms which repeatedly occur, and may invariably be referred to the same general order or system. This system is, or appears to bc, what I may term a homologous series of "oxycarbons," of which the unit of carbon with the weight 12 may be regarded as the first term, and of which the adjacent terms differ by an increment of carbonic oxide (CO) weighing 28 , precisely as homologous series of hydrocarbons differ by the increment $\mathrm{CH}_{2}$ with the weight 14 . I have succeeded in identifying by analysis two at least of these substances, namely, the adjacent terms $\mathrm{C}_{4} \mathrm{O}_{3}$ and $\mathrm{C}_{5} \mathrm{O}_{4}$. From this point of view these peculiar bodies are members of a series of oxycarbons analogous in the oxycarbon system to the series of hydrocarbons of which the unit of carbon is the first and the unit of acetylene $\mathrm{C}_{2} \mathrm{H}_{2}$ is the second term, the oxycarbon $\mathrm{C}_{4} \mathrm{O}_{3}$ being represented in that series by the hydrocarbon crotonylene $\mathrm{C}_{4} \mathrm{H}_{6}$, and the oxycarbon $\mathrm{C}_{5} \mathrm{O}_{4}$ by the hydrocarbon valerylene $\mathrm{C}_{5} \mathrm{H}_{8}$.

\section{THE LAIV OF STORATS DEVELOPED*} III.

FROM the Cape of Good Hope, in a straight line toward the projecting eastern coasts of Brazil, mariners have found a peculiar streakj of south-easterly winds. 